\title{
DETERMINATION OF THE GIANT-BAMBOO PYROLYSIS KINETIC PARAMETERS
}

\author{
P. O. B. HOMRICH ${ }^{1}$, D. TOSS ${ }^{2}$, M. GODINHO ${ }^{2}$, D. PERONDI ${ }^{2}$, C. BROETTO ${ }^{2}$, F. $^{2}$ \\ FERRARINI $^{2}$ \\ ${ }^{1}$ Universidade Estadual de Campinas, Faculdade de Engenharia Química, Departamento de \\ Desenvolvimento de Processos e Produtos \\ ${ }^{2}$ Universidade de Caxias do Sul, Faculdade de Engenharia Química \\ E-mail para contato: phomrich@ @eq.unicamp.br
}

\begin{abstract}
The kinetics involved in giant bamboo thermal degradation under $\mathrm{N}_{2}$ atmosphere was investigated through non-isothermal thermogravimetric analyses (TGA) and derivative thermogravimetry (DTG) applying three isoconversional methods: Coats and Redfern (CR), MacCallum and Tanner (MT), and van Krevelen (VK). Besides that, samples characterization was conducted by van Soest's method and by proximate analysis. The TGA experiments were performed with a $\mathrm{N}_{2}$ rate of $50 \mathrm{~mL} / \mathrm{min}$ and five different heating rates were used: $5,10,15,25$ and $50{ }^{\circ} \mathrm{C} / \mathrm{min}$, for a samples aged 5.5 years. The van Soest's test indicated that the giant bamboo is composed of up to $73 \%$ of cellulose and the proximate analysis showed up to $84 \%$ of volatile matter. The highest weight loss region evaluated by the DTG was between $200-450^{\circ} \mathrm{C}$, corresponding to a weight loss range of $10-85 \%$ in mass. The Coats-Redfern's fitting-model indicated that two-dimensional diffusion was the mechanism which best describes the pyrolysis process in the highest weight loss region. The kinetic parameters determined by CR's, MT's, and MT's methods, respectively, varied between 136 and $150 \mathrm{~kJ} / \mathrm{mol}$ for the activation energy and between $2.75 \times 10^{10}$ and $3.6 \times 10^{11} \mathrm{~s}^{-1}$ for the preexponential factor. Comparing the calculated and experimental weight loss, was verified that the CR's and MT's average deviations were lower than the evaluated by VK's method, indicating that the CR's and MT's describe better the giant bamboo pyrolysis.
\end{abstract}

\section{INTRODUCTION}

The world necessity for clean energy and the continuous Earth's warming due to the high pollutant gases emissions, provokes an increase in research for new environmentally friendly energy sources. Lignocellulosic biomasses are an interesting option to obtain biofuels [Basu, 2010], being mainly composed of cellulose, hemicellulose, and lignin, compounds which present high heating value due to the high carbon contents in their molecules [Glasser, 1985; McKendry, 2002]. Giant bamboo, scientifically known as Dendrocalamus giganteus 
Munro, is a potential material to be transformed into biofuels due to the high cellulose amount in its composition (Raveendran and Ganesh, 1996; Aparicio, 2005), and also, by presenting a high growth rate, growing up to $30 \%$ times faster than the trees species of rapid growth. As verified by Azzini et al (1989), giant bamboo presents a growth rate that lies between 2.00-7.88 $\mathrm{cm} /$ day, and as verified by some previous works, it grows up to 40 meters and can reaches up to $20 \mathrm{~cm}$ diameter (Keng and Wang, 1996; Pereira and Beraldo, 2007).

Pyrolysis is a thermochemical process which transforms biomass into biofuels through material degradation at different heating rates and in total oxygen absence (Maschio et al., 1992; Yaman, 2004). Among the different types of pyrolysis, conventional pyrolysis is performed with a heating rate which varies from 10 to $50^{\circ} \mathrm{C}$. According to Demirbas 2009 , by varying the upper temperature process and the residence time, the conventional pyrolysis products can range from $25-91 \%_{\mathrm{wt}}$ of bio-char, $7-33 \% \mathrm{wt}$ of bio-oil and $2-54 \%$ wt of bio-gas. In order to design an efficient and sustainable pyrolysis reactor, the reaction kinetic parameters, activation energy (E) and pre-exponential factor (A), must be determined (Varhegyi, 1997). Isoconversional methods which determine the kinetic parameters, such as Coats-Redfern (1964), MacCallumTanner (1970), and van Krevelend (1951), use thermogravimetric data to adjust the parameters to attain the best fit to the data experimentally generated. These methods were applied by previous works which studied the thermal degradation of materials, especially for polymeric materials as biomasses, resins, and some selected organic matter, and were related with thermogravimetric data (White et al., 2011; Perondi, 2012).

This research aimed to obtain the kinetic parameters at five different heating rates of conventional pyrolysis of the giant bamboo from specie Dendrocalamus giganteus Munro aged 5,5 years. To attain this purpose, thermogravimetric and derivative thermogravimetry data were obtained and the experimental data was modelled using the isoconversional methods of CoatsRedfern, MacCallum-Tanner, and van Krevelen.

\section{MATERIALS AND METHODS}

\subsection{Materials}

Dendrocalamus giganteus Munro was the giant bamboo specie used in the pyrolysis kinetic parameters determination. The age of the sample studied in this work was 5.5 years, and the material was naturally air-dried previously under ambient conditions and crushed in a knife mill and sieved with Tyler's sieve to obtain particles with a size lower of $0.84 \mathrm{~mm}$ (20 mesh).

\subsubsection{Material Characterization}

The giant bamboo samples compositions were gravimetrically determined by van Soest's method (Soest, 1968), which evaluates the cellulose, hemicellulose and cellular, lignin, and ash contents. The volatile matter, fixed carbon, and moisture were determined by proximate analyses. 


\subsubsection{Thermogravimetric analyses}

The thermogravimetric analyses were performed in a thermobalance (TG-50 Shimadzu) in an inert atmosphere with a $\mathrm{N}_{2}$ flow of $50 \mathrm{~mL} / \mathrm{min}$ in the absence oxygen. The initial mass used in the analyses was around $10 \mathrm{mg}$ and were used five heating rates: 5, 10, 15, 25 and 50 ${ }^{\circ} \mathrm{C} / \mathrm{min}$, characterizing the process as conventional pyrolysis (Demirbas, 2009). The initial and final temperatures were 200 and $800{ }^{\circ} \mathrm{C}$, respectively.

\subsubsection{Kinetics Modeling}

The TG data was used to obtain the ratio loss of samples masses, as shown in equation 1.

$$
\alpha=\frac{\left(m_{0}-m_{t}\right)}{\left(m_{0}-m_{f}\right)}
$$

where $m_{t}$ is the sample weight in the time $\mathrm{t} ; m_{0}$ is the initial sample weight and $m_{f}$ is the final sample weight. The degradation rate depends on the reaction rate $(k)$, which is dependent on the analysis temperature, and depends on the unreacted material function $(f(\alpha))$, which depends on the sample weight, as shown in equation 2.

$$
\frac{d \alpha}{d t}=k \cdot f(\alpha)=A \cdot e^{(-E / R T)} \cdot f(\alpha)
$$

In equation 2, the reaction rate $(k)$ was related by Arrhenius' equation, presenting the dependence of this rate with the kinetic parameters, the activation energy (E) and preexponential factor (A). By variables separation of equation 2 and considering the heating rate $(\mathrm{dT} / \mathrm{dt})$ of the system $(\beta)$, is obtained a dependence between the weight loss and the temperature related with the kinetic parameters, as shown in equation 3:

$$
\int_{0}^{\alpha} \frac{d \alpha}{f(\alpha)}=\frac{A}{\beta} \int_{0}^{T} e^{(-E / R T)} \cdot d T=\frac{A \cdot E}{\beta R} p(x)=g(\alpha)
$$

where:

$$
p(x)=\int_{\alpha}^{x} \frac{e^{-x}}{x^{2}} d x
$$

Resulting in equation 4:

$$
g(\alpha)=\frac{A \cdot E}{\beta R} p(x)
$$

Dividing equation 4 by $\mathrm{p}(\mathrm{x})$ and by applying logarithm on both sides of the equation, one obtains an equation which can be related by linearization, as shown in equation 5 . 


$$
\log g(\alpha)-\log p(x)=\log \frac{A \cdot E}{R \cdot q}
$$

The unreacted material functions $f(\alpha)$ and their integrated inverse forms $g(\alpha)$ for different mechanisms are reported in Table 1 (Fraga and Nunez, 2001).

Table 1 - Unreacted material functions $\mathrm{f}(\alpha)$ and the inverse of its integrate form $\mathrm{g}(\alpha)$.

\begin{tabular}{|c|c|c|}
\hline Degradation mechanism & $f(\alpha)$ & $g(\alpha)$ \\
\hline \multicolumn{3}{|c|}{ Chemical Reaction } \\
\hline First order $(\mathrm{F} 1)$ & $(1-\alpha)$ & $-\ln (1-\alpha)$ \\
\hline Second order (F2) & $(1-\alpha)^{2}$ & $(1-\alpha)^{-1}-1$ \\
\hline Order $n(F n)$ & $(1-\alpha)^{\mathrm{n}}$ & {$\left[(1-\alpha)^{1-n}-1\right]$} \\
\hline & & $\mathrm{n}-1$ \\
\hline \multicolumn{3}{|c|}{ Nucleation } \\
\hline $\begin{array}{c}\text { Bidimensional } \\
\text { Avrami-Erofeev (A2) }\end{array}$ & $2(1-\alpha)[-\ln (1-\alpha)]^{1 / 2}$ & {$[-\ln (1-\alpha)]^{1 / 2}$} \\
\hline $\begin{array}{c}\text { Tridimensional } \\
\text { Avrami-Erofeev (A3) }\end{array}$ & $3(1-\alpha)[-\ln (1-\alpha)]^{2 / 3}$ & {$[-\ln (1-\alpha)]^{1 / 3}$} \\
\hline Prout-Tompkins (PT) & $(1-\alpha) \alpha^{0,5}$ & $\ln \left[\frac{(1+\alpha)^{0,5}}{(1-\alpha)^{0,5}}\right]$ \\
\hline \multicolumn{3}{|c|}{ Diffusion } \\
\hline Bidimensional (D2) & {$[-\ln (1-\alpha)]^{-1}$} & $\alpha+(1-\alpha) \ln (1-\alpha)$ \\
\hline Tridimensional (D3) & $\frac{(2 / 3)(1-\alpha)^{2 / 3}}{1-(1-\alpha)^{1 / 3}}$ & {$\left[1-(1-\alpha)^{1 / 3}\right]^{2}$} \\
\hline Zhuravlev (ZH) & $\frac{(2 / 3)(1-\alpha)^{5 / 3}}{1-(1-\alpha)^{1 / 3}}$ & {$\left[(1-\alpha)^{-1 / 3}-1\right]^{2}$} \\
\hline Ginstling-Brounshtein (G-B) & $\frac{(2 / 3)(1-\alpha)^{1 / 3}}{1-(1-\alpha)^{1 / 3}}$ & $1-\frac{2 \alpha}{3}-(1-\alpha)^{2 / 3}$ \\
\hline \multicolumn{3}{|c|}{ Phase Boundary Reaction } \\
\hline Contracting Sphere (R2) & $2(1-\alpha)^{1 / 2}$ & $1-(1-\alpha)^{1 / 2}$ \\
\hline Contracting Cylinder (R3) & $3(1-\alpha)^{2 / 3}$ & $1-(1-\alpha)^{1 / 3}$ \\
\hline
\end{tabular}

Several methods using different approaches have been developed aiming to solve the term $\log [\mathrm{p}(\mathrm{x})]$ in equation 5 . This work determined the kinetic parameters based on those approximations presented by Coats and Redfern, MacCallum-Tanner and van Krevelen.

\section{RESULTS}

\subsection{Characterization of the giant bamboo samples}

The composition obtained from the van Soest's method confirmed the high concentration of cellulose in giant bamboo, possessing $73 \%$ in mass of this compound. Hemicellulose and some proteins, fats and some fibers amounted $20.1 \%$, while lignin and ash represented 5.3 and $1.6 \%$ in mass, respectively. Based on these results, the giant bamboo presents a high amount of 
volatile matter. It was confirmed by the proximate analysis which indicates that the sample possess $83 \%$ of volatile matter, $9.2 \%$ of moisture and $2.6 \%$ of fixed carbon.

\subsection{Pyrolysis degradation of the giant bamboo samples}

The sample degradation for the five different heating rates is shown in Figure 2. As can be seen in Figure 2, giant bamboo degradation occurs at three different stages. The first weight loss, about $10 \%$ of matter, was due to the water content, being in agreement with proximate analyses results. The second step is noticed by the abrupt weight loss region, where sample decomposition occurred, indicating that approximately $70 \%$ of biomass was consumed. The third stage is verified on the region where a very low degradation rate occurs due to lignin residues and solids and liquids products degradations, like tar and char. As can be observed in Figure 2, the degradation curves presented the same behavior, differing only the reaction time.

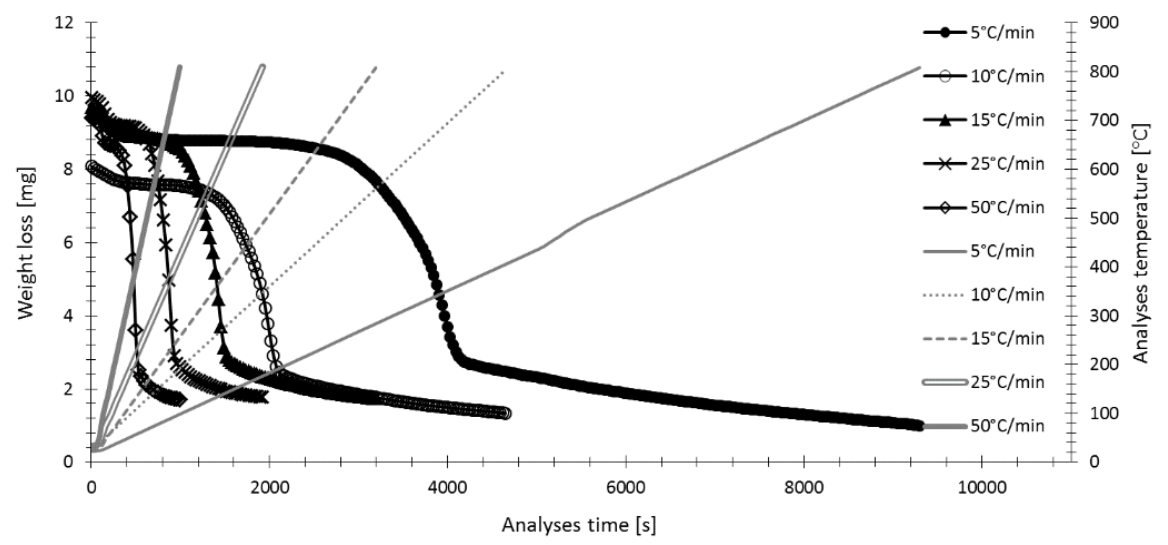

Figure 2 - Weight loss curves and heating rate of sample.

Figure 3 presents the DTG of the giant bamboo. The region covered by the peak in this figure represents the second stage.

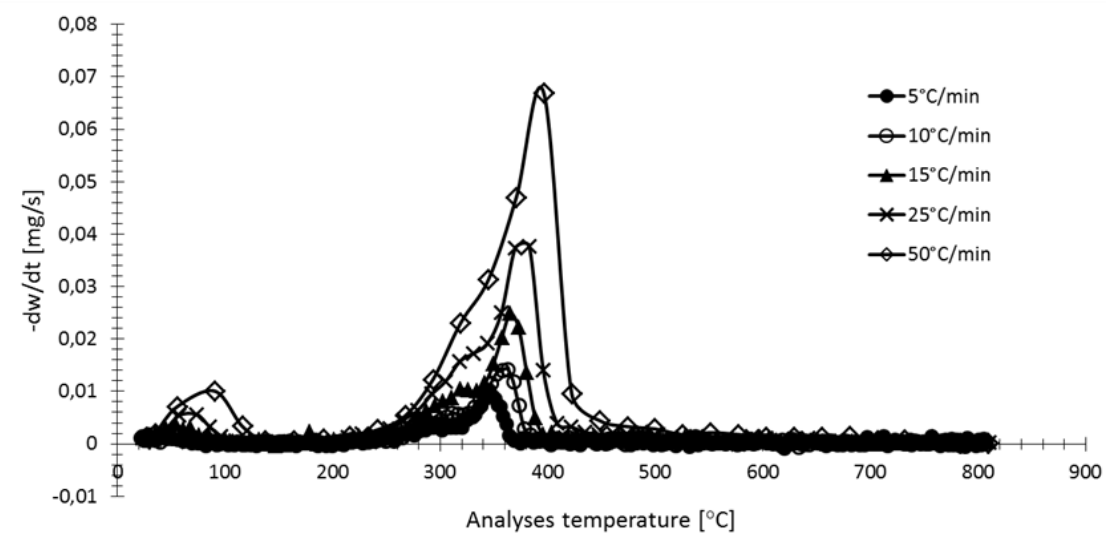

Figure 3 - DTG curves for giant bamboo. 
It is possible to verify that the highest degradation rate occured at $347.9^{\circ} \mathrm{C}$ for the $5^{\circ} \mathrm{C} / \mathrm{min}$ heating rate and at $391.2^{\circ} \mathrm{C}$ for the $50^{\circ} \mathrm{C}$, varying between these values for the others heating rates. Furthermore, it is observed that the abrupt weight loss increase lies between $270-430{ }^{\circ} \mathrm{C}$ and the same behavior occurs for the five different heating rates. The temperature range of samples degradation agrees with those of cellulose, hemicellulose, and lignin estimated ranges (Ramiah, 1970).

\subsection{Determination of the fit pyrolysis process mechanism}

The degradation mechanism was determined using the Coats-Redfern's method. Figure 4 illustrates the relation between $\ln \left[\mathrm{g}(\alpha) / \mathrm{T}^{2}\right]$ and $1 / \mathrm{T}$, indicating the fitting mechanism by data linearization.

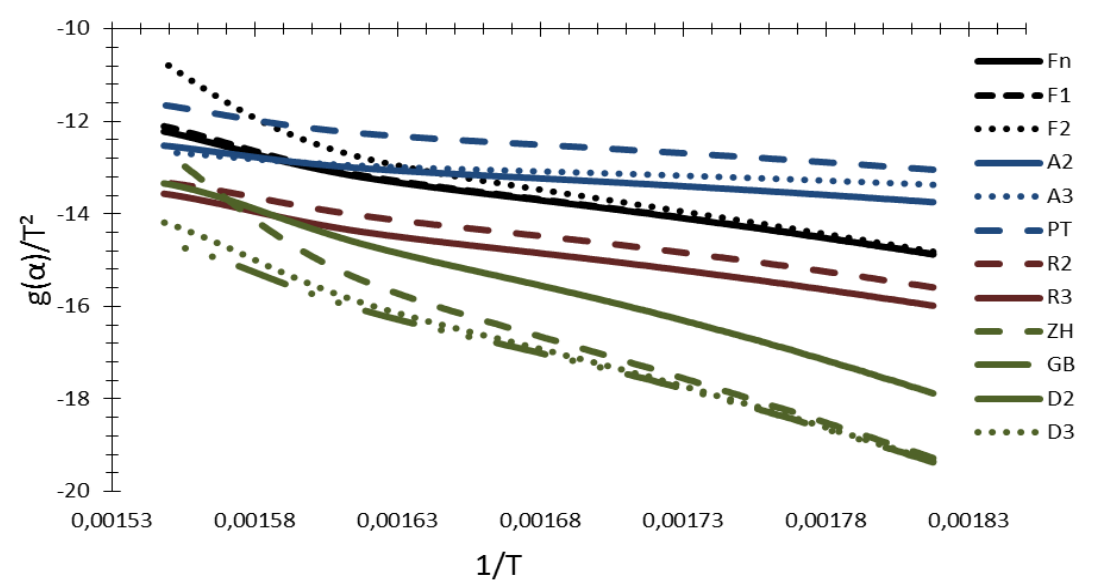

Figure 4 - Mechanism degradation of giant bamboo determined by Coats-Redfern's method.

Each of this curves were linearly related and the best coefficient of determination indicated the degradation mechanism for the giant bamboo. Among those calculated $r^{2}$, the higher was found for the two-dimensional diffusion mechanism, best describing the giant bamboo pyrolysis for the five different heating rates, indicating that the biopolymer material degrades by mass diffusion.

\subsection{Giant bamboo kinetic parameters determination}

The activation energy (E) and the pre-exponential factor (A) were calculated by CoatsRedfern's, MacCallum-Tanner's, and van Krevelen's methods. For the kinetic parameters determination, the $g(\alpha)$ function was consider to be equal to $\alpha+(1-\alpha) \ln (1-\alpha)$, as indicated in Table 1. The kinetic parameters were calculated by the relationship between the angular and linear coefficient from the straight lines obtained by the fitting of CR's, MT's, and VK's methods. The kinetic parameters calculated with these three methods are summarized in Table 2. As can be observed, the parameters determined from CR's and MT's methods presented close values, while the calculated by MT's method differs around $10 \%$. 
Table 2 - Sample kinetic parameters calculated by CR's, MT's, and VK's methods.

\begin{tabular}{|c|c|c|c|c|c|c|}
\hline & \multicolumn{2}{|c}{ Coats-Redfern } & \multicolumn{2}{c|}{ MacCallum-Tanner } & \multicolumn{2}{c|}{ van Krevelen } \\
\hline$\beta$ & $\mathrm{E}[\mathrm{J} / \mathrm{mol}]$ & ${\mathrm{A}\left[\mathrm{s}^{-1}\right]}^{-1}$ & $\mathrm{E}[\mathrm{J} / \mathrm{mol}]$ & $\mathrm{A}\left[\mathrm{s}^{-1}\right]$ & $\mathrm{E}[\mathrm{J} / \mathrm{mol}]$ & $\mathrm{A}\left[\mathrm{s}^{-1}\right]$ \\
\hline 5 & 137771 & $3,10 \mathrm{E}+10$ & 139793 & $4,37 \mathrm{E}+10$ & 150988 & $4,24 \mathrm{E}+11$ \\
\hline 10 & 134903 & $2,14 \mathrm{E}+10$ & 137069 & $3,08 \mathrm{E}+10$ & 147735 & $2,60 \mathrm{E}+11$ \\
\hline 15 & 135327 & $2,52 \mathrm{E}+10$ & 137608 & $3,73 \mathrm{E}+10$ & 149106 & $3,56 \mathrm{E}+11$ \\
\hline 25 & 134920 & $2,60 \mathrm{E}+10$ & 137352 & $3,95 \mathrm{E}+10$ & 148551 & $3,41 \mathrm{E}+11$ \\
\hline 50 & 135493 & $3,35 \mathrm{E}+10$ & 138132 & $5,31 \mathrm{E}+10$ & 149622 & $4,59 \mathrm{E}+11$ \\
\hline
\end{tabular}

The calculated data were determined by equation 5 using the kinetic parameters summarized in Table 2. When were compared with those calculated experimentally, it was observed that CR's and MT's methods determined better the calculated data than VK's method, presenting an average deviation between the experimental and calculated data of 4.39, 4.42 and $4.8 \%$ for CR's, MT's, and VK's methods.

\section{CONCLUSION}

The giant bamboo conventional pyrolysis kinetics was investigated by the CR's, MT's, and MT's isoconversional methods using thermogravimetric data. The CR's method showed that the giant bamboo degradation occurs by two-dimensional diffusion and the DTG presented that the temperature range which reaction occurred was between $200-450^{\circ} \mathrm{C}$. The kinetic parameters obtained by CR's, MT's, and VK's methods varied between 135-137, 138-139 and 149 to $151 \mathrm{~kJ} / \mathrm{mol}$ for the activation energy and between $2.14 \times 10^{10}-3.35 \times 10^{11}, 3.08 \times 10^{10}$ $5.31 \times 10^{10}$ and $2.6 \times 10^{11}-4.59 \times 10^{11} \mathrm{~s}^{-1}$ for the pre-exponential factor. With these values, it is possible to design a pyrolysis reactor to obtain bioenergy from giant bamboo. The relation between the experimental and calculated data showed that the kinetic parameters adjusted with weight loss data through CR's and MT's method described better the giant bamboo pyrolysis than the VK's method, which presented a higher calculated data average deviation.

\section{REFERENCES}

APARICIO, M. G. et al. Evaluation of steam-treated giant bamboo for production of fermentable sugars. Biotechnology Progress, v. 27, p. 641-9, 2011.

AZZINI, A.; CIARAMELO, D.; SALGADO, A. L. B Velocidade de crescimento dos colmos de algumas espécies de bambu. O Agronômico, v. 41, p. 199-200, 1989.

BASU, 2010. Biomass gasification and pyrolysis. Burlington: Academic Press, 2010.

COATS, A. W.; REDFERN, J. P. Kinetic Parameters from Thermogravimetric Data. Nature, v. 201, p. 68-71, 1964.

DEMIRBAS, A. Biorefineries: Current activities and future developments. Energy Conversion and Management, [S.1], v. 50, p. 2782-2801, 2009. 
FRAGA, F.; NUNEZ, E. R. Activation Energies for the Epoxy System BADGE n = 0/m-XDA Obtained Using Data from Thermogravimetric Analysis. J. of Applied Polymer Science, v. 80, p. 776-782, 2001.

GLASSER, W. G. Fundamentals of biomass thermochemical conversion. Elsevier, 1985.

KENG P. C.; WANG, C. P. Flora reipublicae popularis sinicae. Bambusoideae. Science Press, v. 9, p. 155-7, 1996.

MACCALLUM, J. R.; TANNER, J. The Kinetics of thermogravimetry. European Polymer J., v. 6, p. 1033-1036, 1970.

MASCHIO, G.; KOUFOPANOS, C.; LUCCHESI, A. Pyrolysis, a promising route for biomass utilization. Bioresource Technology, v. 42, p. 219-31, 1992.

MCKENDRY, P. Energy production from biomass (Part I): overview of biomass. Bioresource Technology, v. 83, p. 37-46, 2002.

PEREIRA, M. A. R.; BERALDO, A.L. Bambu de corpo de alma. Bauru, SP: Editora Canal 6, 2007.

PERONDI, D. et al. Thermal decomposition of polymer resin [C29H24N2O5)n]: kinetic parameters and mechanisms. Polymer Degradation and Stability, v. 97, p. 2110-2117, 2012.

RAMIAH, M. V. Thermogravimetric and differencial thermal analysis of cellulose, hemicellulose and lignin. J. Applied Polymer Science, v. 14, p. 1323-1337, 1970.

RAVEENDRAN, K.; GANESH, A. Heating value of biomass and biomass pyrolysis products. Fuel, v. 75, p. 1715-20, 1996.

VAN KREVELEN, D. W. et al. Physicochemical aspects of the pyrolysis of coal and related organic compounds. Fuel, v. 30, p. 253-258, 1951.

VARHEGYI, G. et al. Kinetic modeling of biomass pyrolysis. J. of Analytical and Applied Pyrolysis, v. 42, p. 73-87, 1997.

WHITE, J. E.; CATALlO, W. J.; LEGENDRE, B. L. Biomass pyrolysis kinetics: A comparative critical review with relevant agriculture residue case studies. J. of Analytical and Applied Pyrolysis, v. 91, p. 1-33, 2011.

YAMAN, S. Pyrolysis of biomass to produce fuels and chemical feedstocks. Energy Conversion and Management, v. 45, p. 651-671, 2004. 